\title{
Total Synthesis of (+)-Roxaticin
}

Key words

\section{(+)-roxaticin}

cross-metathesis

C-C bond forming transfer

hydrogenation

\section{SYNFACThenth}
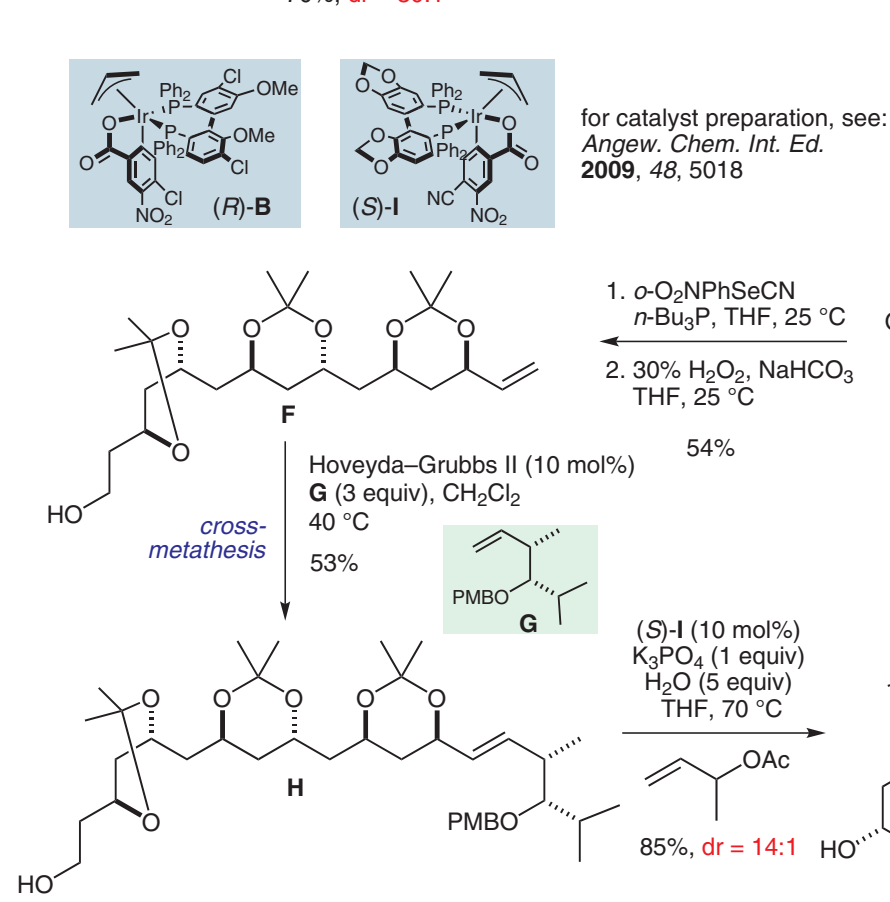

$54 \%$
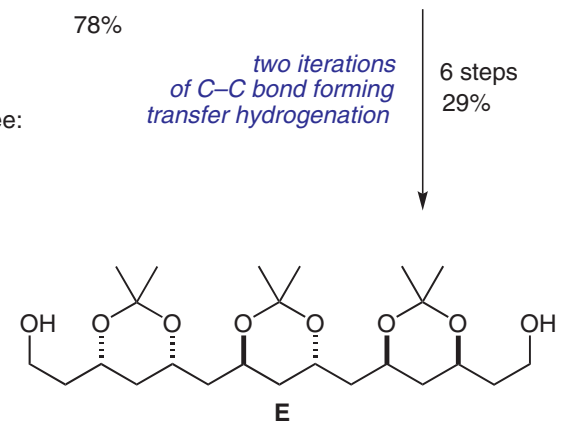

$(\mathrm{MeO})_{2} \mathrm{CMe}_{2}$ $\mathrm{CH}_{2} \mathrm{Cl}_{2}, 25^{\circ} \mathrm{C}$

2. $\mathrm{O}_{3}, \mathrm{CH}_{2} \mathrm{Cl}_{2}-\mathrm{MeOH}$,

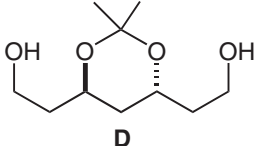

D

$78 \%$ of $C-C$ bond forming
transfer hydrogenation 6 steps $9 \%$

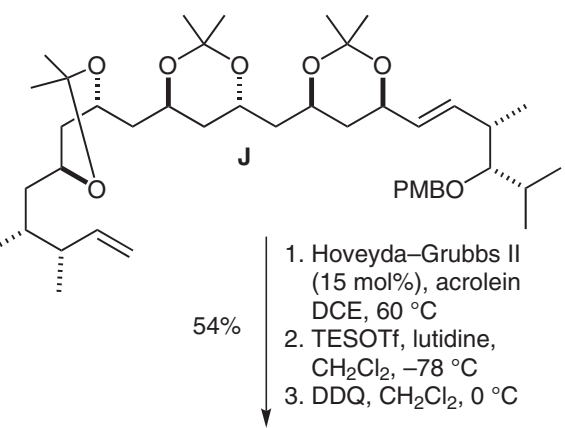<smiles>[X]C1CC(CC2OC(C)(C)OC2CC2CC(C=C[C@@H](C)[C@H](O)C(C)C)OC(C)(C)O2)OC(C)(C)O1</smiles>

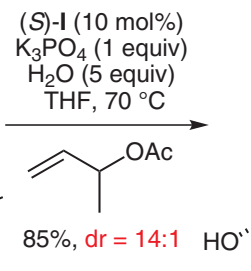

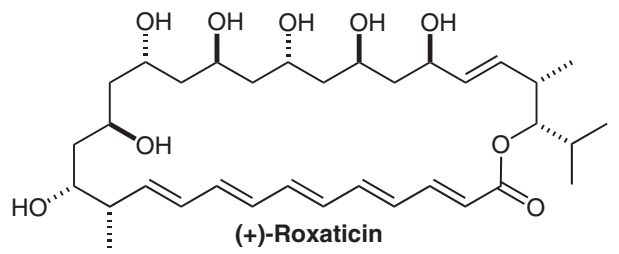

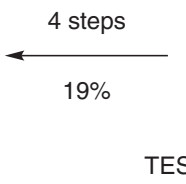

Significance: The oxo-polyene macrolide (+)-roxaticin has been a popular target for the synthetic community. This synthesis requires only 20 steps and is particularly efficient due to a lack of chiral auxiliary controlled reactions and redox manipulations.

SYNFACTS Contributors: Steven V. Ley, Catherine F. Carter Synfacts 2011, 2, 0121-0121 Published online: 19.01.2011 DoI: 10.1055/s-0030-1259215; Reg-No.: N08710SF
Comment: The key step in the synthesis is a C-C bond forming transfer hydrogenation (e.g. A $\rightarrow \mathbf{C}$ ), which is used to form seven $\mathrm{C}-\mathrm{C}$ bonds. 